\title{
Don't look now! Risk stratify first
}

\author{
Virginia R. Litle, MD
}

From the Division of Thoracic Surgery, Department of Surgery, Boston University School of Medicine, Boston, Mass.

Disclosures: Author has nothing to disclose with regard to commercial support.

Received for publication March 30, 2016; accepted for publication March 31, 2016; available ahead of print April $28,2016$.

Address for reprints: Virginia R. Litle, MD, Division of Thoracic Surgery, Department of Surgery, Boston

University, 88 E Newton St, Robinson B402, Boston, MA 02118 (E-mail: Virginia.litle@bmc.org).

J Thorac Cardiovasc Surg 2016;152:533-4

$0022-5223 / \$ 36.00$

Copyright (C) 2016 Published by Elsevier Inc. on behalf of The American Association for Thoracic Surgery

http://dx.doi.org/10.1016/j.jtcvs.2016.03.063

Postoperative venous thromboembolism (VTE) after lung resection increases mortality nearly 8 -fold, ${ }^{1}$ with the risk persisting for longer than 30 days. ${ }^{2}$ As exemplified by the central picture in the article by Raja and colleagues ${ }^{3}$ in this issue of The Journal, a VTE after a pneumonectomy decreases long-term survival for as long as 2.5 years. New strategies are necessary to identify patients who are at increased risk for perioperative VTE after anatomic lung resections. These patients at higher risk may benefit from preventive measures, such as extended anticoagulation prophylaxis after discharge. The Caprini VTE risk assessment model is an individualized screening tool that has been evaluated in multiple specialties and more recently in my own group's retrospective cohort of patients undergoing lung resection for malignancy, in which the VTE incidence increased with Caprini score. ${ }^{4}$

In their article, Raja and colleagues ${ }^{3}$ report an $8.9 \%$ rate of VTE in 112 patients undergoing pneumonectomy who underwent routine postoperative lower extremity screening the day before hospital discharge. This corroborates the findings of Agzarian and associates, ${ }^{5}$ in which there was a

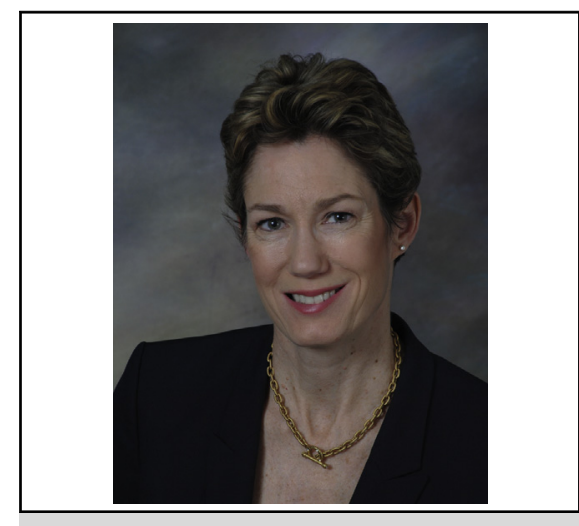

Virginia R. Litle, MD

\section{Central Message}

Venous thromboembolism increases lung resection mortality. Risk stratification identifies higher risk patients for prolonged prevention. Screen the high risk.

See Article page 524.

$12.1 \%$ 30-day VTE rate in patients undergoing anatomic lung resection who were screened not only with ultrasonography but also computed tomography pulmonary angiography. This leads to the "the more you look, the more you see" conclusion in this more recent publication. We can conclude that if VTE decreases long-term survival after pneumonectomies, then we should delineate an early detection and prevention pathway to decrease that

\begin{tabular}{|c|c|c|}
\hline \multicolumn{3}{|c|}{$\begin{array}{l}\text { Proposed Clinical Application of a Caprini VTE Risk Assessment Model throughout the Pre- } \\
\text { operative, Post-operative and Hospital Discharge Phases for Lung Resection Patients }\end{array}$} \\
\hline Pre-operative & Post-operative & Hospital Discharge \\
\hline $\begin{array}{l}\text { - Caprini risk assessment } \\
\text { integrated into pre-op surgical } \\
\text { risk screeninga. } \\
\text { - Patients with Caprini scores } \\
\geq 9 \text { : consider targeted } \\
\text { screening ultrasound. } \\
\text { - DVT(+) on ultrasound: } \\
\text { consider IVC filter, especially } \\
\text { for pneumonectomy. } \\
\text { - Patient education on VTE } \\
\text { risk, symptoms, prevention. }\end{array}$ & $\begin{array}{l}\text { - Caprini risk assessment integrated } \\
\text { into post-operative intake assessment } \\
\text { by primary surgical team. } \\
\text { - Routine standard of care anticoagulant } \\
\text { prophylaxis and compression stockings. } \\
\text { - Minimization of acquired Caprini risk } \\
\text { factors: consider removal of unneeded } \\
\text { central lines, early mobility, proactive } \\
\text { vent wean. } \\
\text { - Patients with Caprini scores } \geq 9 \text { : } \\
\text { consider targeted screening ultrasound. }\end{array}$ & $\begin{array}{l}\text { - Caprini risk assessment integrated } \\
\text { into discharge planning. } \\
\text { - Caprini scores } 5-8 \text { (high risk): } 10 \\
\text { days total post-op prophylaxis with } \\
\text { LMWH or oral direct factor Xa } \\
\text { inhibitors } \\
\text {. } \\
\text { - Caprini scores } \geq 9 \text { (highest risk): } 30 \\
\text { days total post-op prophylaxis }{ }^{b} \text {. } \\
\text { - Patient education regarding VTE } \\
\text { risk, prophylaxis recommendations } \\
\text { with adherence follow up. }\end{array}$ \\
\hline
\end{tabular}

FIGURE 1. Proposed clinical application of the Caprini venous thromboembolism (VTE) risk assessment model throughout the preoperative, postoperative, and hospital discharge phases for patients undergoing lung resection. $D V T$, Deep vein thrombosis; $I V C$, inferior vena cava; $L M W H$, low-molecular weight heparin. 
mortality. The concern about the article in which only screening was used to identify those who had VTE is that symptomatic VTE developed after discharge in an additional $3.6 \%$ of the patients undergoing pneumonectomy, despite negative results of ultrasonography! Screening alone is insufficient. Raja and colleagues ${ }^{3}$ conclude that routine screening or longer prophylaxis for VTE should be considered for identification and (presumably) prevention of VTE. But what else needs to be considered? There are risks and costs associated with such a broad plan. Screening and prolonged prevention cost money. Prolonged prevention may result in bleeding and patient discomfort.

What is the solution? Risk stratification for VTE prevention has been shown to identify those at risk for development of VTE after lung resection. In our preliminary stratification studies of all thoracic surgical patients, VTE rates were almost negated, with minimal associated risks. ${ }^{6}$ Raja and colleagues ${ }^{3}$ reported higher risks in the older patients with chronic obstructive pulmonary disease and those undergoing extrapleural pneumonectomies; thus they are already identifying some risk factors that are supported in the literature (age) and that may need to be included in a model more appropriate for thoracic surgical patients.

What about cost? The reported $60 \%$ reduction in postoperative VTEs with extended-course chemoprophylaxis could result in a significant decrease in health care costs associated with the diagnosis and treatment of VTE complications, which can exceed $\$ 15,000$ per event, not including the additional costs of readmission.

How can we improve VTE rates and postoperative mortality after lung resections? Risk stratification and consideration of incorporation of screening for the patients at higher risk (Figure 1). The more you look, the more you see-but sometimes you need to see the trees and not the forest.

\section{References}

1. Trinh VQ, Karakiewicz PI, Sammon J, Sun M, Sukumar S, Gervais MK, et al. Venous thromboembolism after major cancer surgery: temporal trends and patterns of care. JAMA Surg. 2014;149:43-9.

2. Merkow RP, Bilimoria KY, McCarter MD, Cohen ME, Barnett CC, Raval MV, et al. Post-discharge venous thromboembolism after cancer surgery: extending the case for extended prophylaxis. Ann Surg. 2011;254: $131-7$.

3. Raja S, Idrees JJ, Blackstone EH, He J, Badjatiya A, Mazzone P, et al. Routine venous thromboembolism screening after pneumonectomy: the more you look, the more you see. J Thorac Cardiovasc Surg. 2016;152:524-32.e2.

4. Hachey KJ, Sterbling H, Choi DS, Pinjic E, Hewes PD, Munoz J, et al. Prevention of postoperative venous thromboembolism in thoracic surgical patients: implementation and evaluation of a Caprini risk assessment protocol. J Am Coll Surg. December 18, 2015 [Epub ahead of print].

5. Agzarian J, Hanna WC, Schneider L, Schieman C, Finley CJ, Peysakhovich Y, et al. Postdischarge venous thromboembolic complications following pulmonary oncologic resection: an underdetected problem. J Thorac Cardiovasc Surg. 2016;151:992-9.

6. Hachey KJ, Hewes PD, Porter LP, Ridyard DG, Rosenkranz P, McAneny D, et al. Caprini venous thromboembolism risk assessment permits selection for postdischarge prophylactic anticoagulation in patients with resectable lung cancer. J Thorac Cardiovasc Surg. 2016;151:37-44.e31.

7. Spyropoulos AC, Lin J. Direct medical costs of venous thromboembolism and subsequent hospital readmission rates: an administrative claims analysis from 30 managed care organizations. J Manag Care Pharm. 2007;13:475-86. 